\title{
Erratum to: Inflammatory activation in children with primary hypertension
}

\author{
Mieczyslaw Litwin • Jacek Michałkiewicz • Anna Niemirska • Lidia Gackowska • \\ Izabela Kubiszewska • Aldona Wierzbicka • Zbigniew T. Wawer • Roman Janas
}

Published online: 29 September 2010

(C) IPNA 2010

\section{Erratum to: Pediatr Nephrol}

\section{DOI 10.1007/s00467-010-1548-4}

Unfortunately, one authors' name was published incorrectly.

It should read: Lidia Gackowska.

The online version of the original article can be found at http://dx.doi. org/10.1007/s00467-010-1548-4.

M. Litwin $(\bowtie)$

Department of Research,

The Children's Memorial Health Institute,

Warsaw, Poland

e-mail: m.litwin@czd.pl

M. Litwin · A. Niemirska

Department of Nephrology and Arterial Hypertension,

The Children's Memorial Health Institute,

Warsaw, Poland

J. Michałkiewicz

Department of Microbiology and Immunology,

The Children's Memorial Health Institute,

Warsaw, Poland

J. Michałkiewicz $\cdot$ L. Gackowska $\cdot$ I. Kubiszewska

Department of Immunology,

Nicolaus Copernicus University Collegium Medicum,

Bydgoszcz, Poland

A. Wierzbicka $\cdot$ Z. T. Wawer

Department of Biochemistry and Experimental Medicine,

The Children's Memorial Health Institute,

Warsaw, Poland

R. Janas

Department of Radioimmunology,

The Children's Memorial Health Institute,

Warsaw, Poland 